\title{
BASIL CLEVELAND
}

\section{Tactics}

\section{THE STUDY OF WARFARE}

It is like a theater of metallurgy, the stage massed with alloy figures, and we study them-

but without the stage, and the figures go their readiness uncued, as if by internal assent each lusters

forward, some bending this way, others not.

\section{THE HISTORY OF WARFARE}

The ceramicist made himself a ceramic knife.

I will cuff the beehive, he said, and the narrow timbre of the bees

will polish the room with blue light.

Now ceramic deer flee their pitiful containers. 